\title{
A Confusão Esquerda/Direita no Mundo Pós-Muro de Berlim: Uma Análise e uma Hipótese
}

Angelo Segrillo

\begin{abstract}
$A$ s linhas divisórias entre esquerda e direita tornaram-se bem menos nítidas nos últimos anos (ou mesmo desapareceram, segundo alguns autores). A queda do Muro de Berlim em 1989 e o desaparecimento da União Soviética - URSS (União das Repúblicas Socialistas Soviéticas) em 1991 foram acontecimentos que marcaram profundamente esse processo, tendo simbolizado para muitos a derrubada também do "muro" entre a esquerda e a direita. Ou seja, seria o Big $B a n g$, que iniciou a era em que partidos de esquerda assumem posições de direita em certas questões cruciais e vice-versa, o que tornaria irrelevante a rotulação esquerda/direita.

O autor das presentes linhas presenciou na União Soviética o que talvez tenha sido o início do processo de embaralhamento desses conceitos nos anos 90. Ao chegar em Moscou, em 1989, para realizar seu curso de Mestrado, ficou surpreso com um fenômeno político deveras original: em meados da Perestroika, comunistas ortodoxos eram chamados de "direita" e pessoas que defendiam um avanço para uma economia de mercado eram rotulados de "esquerda"! Convenhamos que a situação era esdrúxula em termos políticos tradicionais, pois geralmente o comunismo e o socialismo estão associados com a esquerda, e a defesa do capitalismo mais com o lado direito do espectro.
\end{abstract}

DADOS - Revista de Ciências Sociais, Rio de Janeiro, Vol. 47, nº3, 2004, pp. 615 a 632. 
Essa "troca de sinais" ${ }^{1}$ na URSS na época era explicável da seguinte maneira. Quando Gorbachev iniciou a Perestroika procurando democratizar as instituições soviéticas, dar maior autonomia às empresas estatais etc. e a economia não mostrava sintomas de melhora, houve uma "fase de transição", em 1988, em que ocorreu uma grande luta política nos bastidores do politburo do Partido Comunista da União Soviética - PCUS entre os comunistas mais ortodoxos (liderados por Yegor Ligachev, resistiam às mudanças e queriam "voltar atrás" a um modelo de planejamento central mais tradicional) e aqueles (liderados por Aleksandr Yakovlev) que desejavam "ir adiante" e utilizar "mecanismos de mercado" para tornar a economia socialista mais eficiente (ainda não se utilizava a palavra capitalismo, e sim o eufemismo economia de mercado, sempre se enfatizando que o objetivo não era substituir o socialismo, e sim torná-lo mais eficiente). Neste momento crucial, em 1988, parecia que o progresso em direção a uma sociedade melhor (mais eficiente, mais justa etc.) estava com os que defendiam as reformas, por isso os comunistas ortodoxos eram considerados a "direita" (i.e., reacionários) e os reformistas (muitos dos quais dali a um ou dois anos estariam defendendo o capitalismo em sua versão social-democrática) recebiam o rótulo de "esquerda" (na qualidade de reformistas progressistas) ${ }^{2}$. Ou seja, por um tempo, na URSS tivemos o comunismo na direita e o capitalismo ("economia de mercado") na esquerda!

A situação acima descrita seria corrigida no período final da União Soviética e no início da nova Rússia capitalista, quando ficaram mais bem definidos os papéis reais de cada um dos atores na cena política, os comunistas voltaram a ser esquerda e os capitalistas foram para o lado mais direito do espectro. Entretanto, nos anos 90, a confusão instalou-se nos próprios países capitalistas. O fim da URSS tirou o grande referencial "real" (material) do movimento comunista. Sem ele, considerável parte da esquerda comunista (e socialista) sentiu-se perdida teórica e praticamente. Foi nesse vácuo que surgiu a versão acadêmica da idéia milenarista de O Fim da História, pela obra de Francis Fukuyama (1992), o qual, levando em consideração a virtual derrota nesse final de século de todas as alternativas políticas à democracia liberal (comunismo, fascismo, ditaduras militares ou teocráticas etc.), vaticinou que talvez essa fosse a forma última e mais avançada na progressão das sociedades humanas. 
Difícil imaginar uma situação filosoficamente mais desesperadora para as esquerdas (especialmente a socialista / comunista). Nesse admirável mundo novo simplesmente não sobraria espaço para elas. Acossada por ataques do tipo "fukuyâmico" no campo teórico e pela inapelável dissolução da União Soviética no terreno prático, uma parte da esquerda, sem conseguir enxergar saída para uma mobilização do tipo tradicional, partiu para uma solução teórica no modelo "um passo atrás, dois à frente": a incorporação da idéia de que as divisões clássicas entre esquerda e direita já não podiam ser mantidas.

O pensador mais emblemático dessa corrente, tanto por sua profundidade teórica quanto pela influência prática que suas idéias tiveram sobre os governos de Tony Blair e Gerhardt Schroeder, é Anthony Giddens. Em seu livro Beyond Left and Right (de 1994), o pensador britânico expõe a idéia de que a sociedade atual (pelo menos nos países com grau suficiente de modernidade) é extremamente complexa, e as tradicionais divisões esquerda/direita não constituem mais referenciais suficientes para a formulação de políticas adequadas. Em obra posterior (The Third Way: The Renewal of Social Democracy, de 1998), Giddens sistematiza uma série de preceitos (chamada de "terceira via") para que a social democracia consiga reconquistar o público de maneira ativa e eficiente socialmente. Ao contrário da esquerda clássica, sempre às voltas com as questões macro da sociedade, tratando os cidadãos em termos de massa a ser conduzida, e, por isso mesmo, freqüentemente não conseguindo tocar as pessoas em seus problemas no micro do cotidiano, Giddens propõe a utilização do que chama de life politics. Por esta "política da vida", a nova "esquerda-do-centro" da terceira via deveria não apenas trabalhar as grandes questões de justiça social, eficiência da economia e outras, mas também as questões que afetam os indivíduos pessoal e diretamente, o que significa também ouvir o que estas pessoas têm a dizer sobre suas próprias vidas. Ao invés de adotar a atitude freqüentemente altiva e elitista de "sabe-tudo", de como resolver os problemas dos cidadãos (típica da esquerda antiga), a nova esquerda-do-centro deverá estar antenada com os anseios (inclusive mais pessoais) de seus cidadãos, coisa que às vezes a esquerda faz menos que a direita. Ou seja, diversas bandeiras (da liberdade individual, do direito de escolha, da segurança pessoal), que no passado a direita e a centro-direita quase que monopolizaram, devem ser reapropriadas pela esquerda ${ }^{3}$. 
É fácil ver como a adoção dessa agenda pode levar a uma perda de nitidez dos limites do espectro ideológico. Por exemplo, é significativo que, no caso da excessiva imigração ilegal na Europa, um tema geralmente adotado pela direita, Giddens (2002) pregue que a esquerda enfrente essa questão (uma preocupação real de boa parte dos trabalhadores europeus) de frente com o lema "duro com a imigração, mas também duro com as causas que levam a hostilidade aos imigrantes". Igualmente, Giddens (2000:4) aprova slogans similares usados por Tony Blair na Grã-Bretanha: "Duro com o crime, mas também duro com as causas do crime" e "Mais professores, mais profissionais paramédicos, mais policiais" .

Para o bem ou para o mal, foi com essa agenda da terceira via que a esquerda trabalhista ou social-democrata conseguiu voltar ao poder nos anos 90 em países importantes da Europa Ocidental, como Grã-Bretanha e Alemanha, após um longo período de afastamento. Apesar dos problemas teóricos envolvidos na formulação do conceito de terceira via, o fato de os social-democratas terem voltado ao poder por intermédio de uma plataforma desse tipo inevitavelmente coloca a pergunta: haveria uma alternativa a ela na prática?

Por enquanto, deixemos a prática de lado e retornemos à teoria. A posição de Norberto Bobbio era emblemática daqueles na esquerda que se recusavam a aceitar o fim do espectro ideológico como válido. Em seu livro Destra e Sinistra (1994), publicado no mesmo ano de Beyond Left and Right de Giddens (1994), Bobbio torna-se o grande contraponto simbólico do sociólogo britânico na medida em que se recusa a aceitar o fim da validade da divisão tradicional entre esquerda e direita. Segundo o pensador italiano, no fundo, o que distingue a esquerda da direita é seu posicionamento diante da idéia de igualdade. Para a esquerda, as desigualdades têm causas sociais e devem ser eliminadas; para a direita, as desigualdades são naturais e portanto inevitáveis. Além disso, o posicionamento perante a liberdade diferencia moderados de extremistas. Os extremistas chegam a empregar métodos autoritários para atingir seus fins, enquanto os moderados se refreiam disso. Da interseção desses elementos, tem-se o quadrante básico do espectro ideológico: extrema-esquerda (igualitários autoritários, do tipo jacobinos ou bolchevistas), centro-esquerda (igualitários libertários, do tipo social-democrático), centro-direita (libertários inigualitários, do tipo liberais conservadores) e extrema-direita (autoritários inigualitários, e.g., fascistas). 
Tem-se, assim, os dois grandes contrapontos teóricos da esquerda atualmente. Aqueles que, como Bobbio, acreditam que a tradicional divisão esquerda-direita ainda continua válida, ou os que, como Giddens (1994:78), pensam que "os termos esquerda e direita não têm mais o sentido que tinham, e suas perspectivas políticas estão, à sua maneira, exauridas".

Toda essa retórica exposta acima teve reflexos importantes na vida política brasileira. A confusão ideológica advinda da queda do Muro de Berlim e do fim da URSS atingiu em cheio a esquerda brasileira e afetou suas relações com a direita. No setor mais diretamente ligado à União Soviética, o PCB, as conseqüências foram terríveis. O partido simplesmente rachou. Em seu X Congresso, em 25-26 de janeiro de 1992, o partido foi declarado extinto. A parte hegemônica de seus dirigentes considerava esgotado o modelo bolchevista da III Internacional e, portanto, partiria para a fundação de uma organização mais afinada com as necessidades do socialismo moderno: o PPS. Somente com muita luta nos tribunais, uma parte de militantes e dirigentes que não haviam concordado com a autodissolução conseguiu reaver, em 1995, na justiça brasileira, o direito de utilizar legalmente a sigla PCB, mantendo a agremiação em existência.

Mas não foram apenas os comunistas os afetados com a nova situação pós-Muro de Berlim. Outros partidos de esquerda sofreram pressões fortes para modificar seu perfil ideológico. Na verdade, pode-se dizer que todas as eleições presidenciais desde 1989 foram afetadas por essa reconfiguração do campo político. Em 1989, no ardor dos acontecimentos que levaram à queda do Muro, a campanha de Collor procurava insistentemente associar o concorrente Lula ao estatismo retrógrado ligado à tradição da esquerda de influência soviética. O desaparecimento final da URSS em 1991 aprofundaria o quadro de confusão ideológica esquerda-direita. Um grande exemplo disso seriam os dois governos de Fernando Henrique Cardoso (de 1994 e 1998). Os caminhos do PSDB ilustrariam bem a nova fluidez das fronteiras ideológicas. A maioria dos analistas classificava o PSDB na centro-esquerda quando de sua criação (e.g. Kinzo, 1993; Meneguello, 1994; Novaes, 1994). Afinal, era o Partido da Social Democracia Brasileira. Por exemplo, Meneguello (1994), analisando o espectro político brasileiro pós-eleições de 1989, classificava o PSDB como centro-esquerda, enquanto o PMDB formava o centro do sistema. A estória torna-se outra após 1994, com a chegada do PSDB à presidência. 
Uma retórica de superação das divisões ideológicas clássicas (muitas vezes colocada como uma necessidade imposta pelos imperativos dos processos de globalização) foi um dos fundamentos justificativos da grande aliança parlamentar com partidos de centro e direita (PMDB, PTB, PFL, PL e PPB, em diferentes épocas dela participaram). Tanto que, após a eleição presidencial de 1994, a maioria dos analistas passou a classificar o PSDB como partido de centro junto com o PMDB (e.g. Fernandes, 1995; Limongi e Figueiredo, 1995; Meneguello, 1998).

Essa mudança de classificação do PSDB não significa um mero pequeno deslocamento formal de um partido no espectro ideológico (de centro-esquerda para centro). Na verdade, ela é sintomática de um fenômeno mais abrangente que ocorre na arena política brasileira (como de resto em diversos outros países): a confusão conceitual da esquerda levar partidos de esquerda e centro-esquerda a encaminhar políticas e alianças de cunho ideológico igualmente confuso. É claro que outras motivações de caráter mais prático e mundano estiveram por trás da junção centro-esquerda/centro/direita (PSDB/PMDB / PTB / PL/PFL/PPB): desde a necessidade de alianças (ou acordos) parlamentares para governar quase que inerente aos sistemas democráticos não bipartidários até o tradicional fisiologismo da política brasileira. Mas isto tudo não deve nos cegar para o fato de que a confusão conceitual por que passou a esquerda mundial no mundo pós-Muro de Berlim e pós-URSS teve reflexos na tomada de posição de partidos de esquerda e centro-esquerda também no Brasil em relação a uma redefinição de caminhos para o futuro.

Tanto isso é verdade (e não uma simples estratégia eleitoral de um partido específico, o PSDB, para governar) que, mesmo depois de passada a longa era FHC e tendo subido ao poder um partido (o PT) que todos os analistas políticos brasileiros citados acima não hesitavam anteriormente em classificar de "esquerda" em seus trabalhos, esse padrão de confusão dos rótulos tradicionais de esquerda/direita parece continuar. A eleição de Luiz Inácio Lula da Silva para presidente em 2002 foi marcada por uma aliança de campanha com um partido à direita do centro (o Partido Liberal, que nomeou o candidato a vice-presidente na chapa de Lula) e por uma aliança parlamentar com o eterno partido "governista" do centro, o PMDB (além, é claro, dos pequenos partidos de esquerda, tradicionais aliados do PT). A eleição citada ainda é um fato recente no momento em que este artigo 
está sendo redigido, mas as primeiras medidas do governo Lula em 2003 deixam entrever uma linha política que nem sempre poderá ser chamada de tradicional de esquerda. O próprio fato de a transição para o novo governo ter sido absorvida sem grandes choques pelo empresariado nacional e pelo próprio Fundo Monetário Internacional - FMI (que elogiou as medidas tomadas) é sintomático de que a linha política não contém elementos fortemente confrontantes com o status quo da direita tradicional. O governo Lula não apenas se comprometeu a atingir as metas propostas pelo FMI, como, por conta própria, aumentou a meta do superávit fiscal primário por intermédio de um corte nos gastos do governo que diminuiu as verbas necessárias para vários projetos na área social e de investimentos. Ou seja, não seria de admirar se dentro de pouco tempo aqueles mesmos analistas políticos brasileiros citados acima, que anteriormente não hesitavam em classificar o PT como partido de "esquerda", passem a classificá-lo de "centro-esquerda", em um movimento de "um passo" à direita semelhante ao que o PSDB deu na escala ideológica ao chegar ao poder.

Aqui, eu gostaria novamente de enfatizar que vejo esses movimentos do PSDB, PT e outros em direção ao centro não apenas como mera eventualidade eleitoral de partidos ao chegar ao poder, mas como parte de um contexto político mundial especifíco ("pós-Muro") que está redefinindo as fronteiras ideológicas em diferentes partes do espectro político. Obviamente, as agremiações mais afetadas foram as da esquerda (com a queda do socialismo real no Leste europeu), mas as do lado direito do espectro também estão sendo atingidas. Após um período inicial de "euforia" no final da década de 80 e início da de 90, em que parecia que o capitalismo simplesmente tinha triunfado sobre o socialismo (comunismo) e a direita sobre a esquerda, as dificuldades enfrentadas pelos países capitalistas (principalmente os subdesenvolvidos e em desenvolvimento, mas não apenas) nesse brave new world da globalização impedem a direita de "curtir" com tranqüilidade os louros da vitória. As crises de insegurança, desemprego e outras fazem com que o eleitorado ponha e deponha governos de esquerda e direita. Ocorre, assim, um "movimento em direção ao centro" (onde a maioria do eleitorado parece se localizar) principalmente quando os partidos chegam ao poder. Esse movimento, de modo nenhum exclusivo dessa época, já tendo acontecido em vários momentos no passado, está, entretanto, extremamente facilitado pela apa- 
rente dissolução das fronteiras tradicionais entre esquerda e direita, $\mathrm{o}$ que o torna mais visível e, inclusive, mais provável.

Entretanto, o fato de a direita ser afetada por uma crise ideológica que a princípio deveria dizer respeito apenas à esquerda (i.e., a crise "pós-Muro"), não surge apenas em decorrência do fator apontado no parágrafo acima. Acredito que há um mecanismo teórico mais profundo envolvido. É o que passarei a descrever agora.

De maneira geral, as teorias políticas utilizam o esquema direita/centro/esquerda para a descrição ideológica das agremiações partidárias. Freqüentemente, a esquematização do sistema de coordenadas é baseada na interação entre esquerda e direita. $\mathrm{O}$ centro seria resultado da interação entre os dois extremos. Se o sistema se desloca mais para a esquerda, o centro assim o faz (ou deveria fazer); o mesmo, apenas com sinal invertido, acontece se o sistema se move para a direita. Como colocou Sartori (1966:157), “o centro é relativo à sua esquerda e à sua direita",

“A pergunta crucial é: como e quando a percepção do 'centro' surge com relação a um partido visto como 'ocupando' o centro? Entra aqui em jogo a noção de elasticidade espacial, pois a percepção de um centro é função da extensão do espaço. Um espaço curto não permite, ou não facilita, a percepção de um centro: não tem, por assim dizer, lugar para ele. Um espaço curto é definido simplesmente pelos seus extremos: esquerda e direita. Um terceiro ponto de referência - o ponto central — só adquire significação e se torna perceptível quando o espaço se estende e, particularmente, quando os pontos extremos desse espaço são percebidos como constituindo dois polos à parte." (Sartori, 1982:379).

Ou de acordo com a opinião pioneira (e que revelava um claro viés "bipartidarista" em sua análise dos sistemas partidários) de Maurice Duverger:

“[...] as opções políticas se apresentam, comumente, sob a forma dualista [...] Toda política implica escolha entre dois tipos de soluções: as soluções chamadas intermediárias se relacionam umas com as outras; o que equivale a dizer que o centro não existe em política: pode existir partido de centro, mas não tendência do centro, doutrina do centro. Chama-se 'centro' o lugar geométrico em que se juntam os moderados das tendências opostas, moderados da direita e moderados da esquer- 
da. [...] o centro não é mais que o agrupamento artificial da parte direita da esquerda e da parte esquerda da direita." (Duverger, 1980:250-251)

Ou seja, apesar de seu papel importantíssimo na política, como ponto de equilíbrio do sistema, o centro não se determina por si mesmo, sendo derivado das interações entre esquerda e direita. Assim, o sistema partidário, de modo geral, seria determinado pelas relações recíprocas entre seu lado esquerdo e direito. Na verdade, gostaria de ir um passo adiante e lançar aqui uma hipótese para discussão. Se por um lado o equilíbrio do sistema (i.e., sua estática) é determinado pela interação entre esquerda e direita ${ }^{4}$, postularei que a dinâmica do sistema tem seus impulsos genéticos basicamente a partir da esquerda. O que quero dizer com isso? A interação entre os componentes do sistema o faz atingir um equilíbrio (mais ou menos estável) à medida que se consolida. Na época capitalista, ceteris paribus, sendo esse equilíbrio aceitável para a burguesia dominante, a direita tradicionalmente executa o trabalho de manutenção do status quo. Ou seja, ela é pela manutenção do sistema como ele se apresenta naquele equilíbrio aceitável à classe dominante. Nesse contexto, é da esquerda que partem os movimentos para modificações no sistema. Insatisfeitos com o status quo, setores da esquerda (principalmente socialistas e comunistas) partem para a luta política (que, às vezes, pode chegar às raias do revolucionarismo "extra-sistema") por mudanças radicais naquele equilíbrio partidário que lhes é prejudicial. Assim, a direita, em um contexto teórico-abstrato, é a mantenedora do status quo $0^{5}$, enquanto a esquerda luta pelas transformações. As mutações no sistema serão, em última análise, determinadas por estímulos iniciais provindos da esquerda. Em reação a estes estímulos, a direita movimenta-se, podendo promover "contra-mudanças", i.e., transformações no sentido contrário ao pretendido originalmente pela esquerda. Assim, o sistema poderá se mover para a esquerda e para a direita por intermédio dos diferentes graus de estímulo e esforço provindos dos dois lados, mas não podemos esquecer que o estímulo original, ceteris paribus, provém da esquerda, pois a direita é, em geral, mantenedora dos status quo relacionados ao presente ou passado, enquanto a esquerda propõe transformações em direção a um futuro diferente. Simplificando um pouco, é possível dizer que, nas análises da dinâmica (i.e., do ponto de vista das mutações) do sistema partidário, a esquerda age e a direita reage. 
O que foi dito acima está sendo lançado como hipótese para discussão, mas existem indícios fortes na história brasileira e mundial que apontam nessa direção. Se analisarmos as transformações políticas mais radicais da direita do Brasil no século XX (e.g., ditadura do Estado Novo, Golpe de 64), veremos que elas vêm como processos reativos a momentos em que a classe trabalhadora (em movimentos de "esquerda") estava em ascensão e ameaçava o equilíbrio político "aceitável" pela classe dominante. Isto é absolutamente claro em 1964, mas o processo nos anos 30 que levou à ditadura "paternalista" de Vargas também representou uma reação para desviar o movimento embrionário de ascensão autônoma da classe trabalhadora para um modelo populista de desenvolvimento "atrelado" do proletariado ${ }^{6}$. Na Rússia (país de especialidade do autor do presente ensaio), nos períodos em que há um sistema multipartidário (pré-outubro de 1917 e pós-1990), o caso da esquerda fica óbvio na ascensão do partido bolchevique ao poder e no papel, hoje em dia, do Partido Comunista da Federação Russa, que é o adversário eleitoralmente mais forte do status quo capitalista. Um interessante programa de pesquisa seria realizar um trabalho de política comparativa em um grande número de países para testar a hipótese da esquerda como primum mobile de alterações radicais na dinâmica dos sistemas partidários (também nesse caso seria interessante investigar se existem diferenças nesse aspecto entre sistemas multipartidários e bipartidários).

\section{EXCURSUS}

Nos parágrafos acima, conduzi o raciocínio de maneira relativamente linear para poder chegar à conclusão e à hipótese que queria demonstrar. Pelo caminho deixei de lado algumas arestas que não impediram a passagem de nosso omnibus intelectual, mas que merecem ser comentadas com o objetivo de clarificar nossa própria posição e também tornar mais suave a vinda de futuros viajantes que queiram compartilhar do caminho teórico aqui proposto.

Primeiro de tudo, é óbvio que, em minha análise de esquerda/centro/direita, estou me apoiando prioritariamente na clivagem tradicional de classe para a identificação de posições políticas. Partindo de um ponto de vista marxista, estou trabalhando no nível mais alto de abstração teórica em que o conflito de classes é postulado como o grande locus inicial de deslanchamento das diferenciações nos modernos sistemas partidários. Naturalmente, não ignoro a influência 
de outras clivagens (religiosas, étnicas etc.) na determinação concreta e mais detalhada de diversos sistemas partidários atuais.

Outro ponto relevante se refere à importância da esquerda, direita e centro na determinação do equilíbrio dos sistemas partidários. Como foi colocado anteriormente, a ortodoxia nesse campo era seguir a visão de Duverger e Sartori, que tendiam a subestimar a importância do centro e enfatizar as interações entre a esquerda e a direita como principais influências no equilíbrio dos sistemas partidários. Neste ponto, Duverger (1980:250) é o mais radical: nega a possibilidade, mesmo teórica, que possa ao menos existir algo como uma verdadeira "tendência de centro, doutrina de centro". Sartori (1982:160; 232), apesar de admitir a possibilidade de uma "tendência de centro", reafirma que, na prática, em geral, o centro "tende a imobilizar-se". Ou seja, seguindo esses dois patriarcas dos estudos de sistemas partidários, a maioria dos autores tradicionalmente tendia a encarar o centro como um reflexo do debate entre os extremos, sem grande capacidade de geração de políticas próprias. Essa situação sofreu suas primeiras contestações teóricas mais sérias a partir de meados da década de 1980. Aqui é com prazer que notamos que caráter pioneiro teve uma autora brasileira, Lúcia Hippolito. Hippolito (1985) fez uma análise da atuação do PSD na República brasileira de 1945-64 e demonstrou que este partido de centro, por muitos anos, atuou como um ponto de equilíbrio, verdadeiro "fiador" (e "amortecedor de choques") do sistema partidário como um todo (pelo menos até o final dos anos 50, a partir de quando a polarização e fragmentação interna do partido contribuíram para a própria polarização do sistema partidário brasileiro). Hippolito (idem:35-36) extraiu conclusões teóricas dessa situação descrita, afirmando que "é preciso rediscutir a questão do centro: Se o partido de centro é o fiador da estabilidade política, os abalos sistêmico ocorridos em seu interior constituem condição suficiente para que o sistema partidário deixe de ser moderado e ingresse no grupo dos sistemas pluralistas polarizados".

O que Lúcia Hippolito lançou foi desenvolvido por Timothy R. Scully em seu estudo sobre o Chile. Scully, postulando que o centro pode desempenhar um papel político determinante e fundamental para certos sistemas partidários, afirmou:

"A investigação de mais de 12 décadas de competição partidária no Chile indica que a existência de um centro que aja como um intermediário entre os extremos pode ser necessária para manter o sistema 
partidário integrado. $\mathrm{O}$ centro pode agir como um mediador entre os extremos, absorvendo choques potenciais ao sistema provindos dos dois pólos [...] A experiência do Chile sugere que das diferenças na saliência relativa da clivagem principal resultam dois tipos diferentes de partido de centro: posicionais e programáticos. Um partido de centro posicional ocupa a posição do meio ao longo do eixo principal da clivagem sem um compromisso substantivo com nenhum conjunto particular de políticas ou de resultados. Em contraste, um partido de centro programático possui um programa intermediário específico ao qual se atém e sobre o qual pode não querer fazer compromissos. Um partido posicional tende a ver, como sua raison d'être, conquistar o controle do governo e mantê-lo. Para este fim, o partido facilmente se predispõe a fazer coalizões eleitorais e de governo com partidos à sua direita e à sua esquerda e mesmo com ambos simultaneamente. Como os Liberais [do século XIX] e os Radicais [da primeira metade do século XX] no caso chileno, o centro posicional desfruta de considerável liberdade para agir como um intermediário entre os dois pólos [...] Contrariamente ao que se tem argumentado, a presença deste tipo de centro pode ser essencial para tornar a competição eleitoral possível [...] Em contraste, um centro programático tem uma identidade partidária ('perfil' partidário) que deriva fundamentalmente do eixo predominante de clivagem dentro do sistema partidário. Quando um partido é formado na base de uma posição centrista no eixo predominante de clivagem, e se coloca no centro eleitoral, encontrará muita resistência (tanto dentro do partido quanto fora dele) para cumprir o papel de mediador entre os extremos. [Este foi o caso dos Democrata-Cristãos chilenos que...] [...] emergiram como o centro de um espectro partidário baseado em classe no final dos anos 1950 e se tornaram cada vez menos tendentes e capazes de fazer o papel de intermediários entre a direita e a esquerda" (Scully, 1990).

Assim, nas últimas décadas, foi lançado um desafio à tradicional posição duverger-sartoriana que subestimava o papel autônomo do centro e via o equilíbrio dos sistemas partidários em termos basicamente de interações entre a esquerda e a direita. Ou seja, a nova concepção afirmava que o equilíbrio partidário era determinado pela interação entre esquerda, direita e centro.

Em meu trabalho problematizo os esquemas acima, postulando um papel especial da esquerda nas alterações radicais da dinâmica dos sistemas partidários. 
Sobre um possível papel especial da esquerda é interessante também resgatar a posição de Cerroni (1973:22; 141-142) que, aprofundando e radicalizando as opiniões de alguns autores anteriores (como Morandi, 1963), nega a visão duvergeriana dos grupos parlamentares e comitês eleitorais como origem dos modernos partidos políticos e afirma que os partidos socialistas europeus foram os verdadeiros pioneiros nesse campo. Ou seja, Cerroni insiste peremptoriamente no papel primordial da esquerda no Big Bang criador dos modernos sistemas partidários.

Finalmente, quero esclarecer que o meu recorte "pós-Muro de Berlim" não tem nada a ver com as teses de "Fim da Ideologia" (does it ring a Bell?) ou "Fim da Política" (a visão de fundo kirchheimeriano de que os partidos políticos relevantes de esquerda ou direita se estejam transformando em catch-all parties) (Bell, 1960; Kirchheimer, 1966). Como bem afirmou um parecerista anônimo deste artigo, "em princípio, não há por que imaginar que a crise ideológica atual [da esquerda] tenha sido mais grave e mais profunda do que, por exemplo, a de 1914, quando a social-democracia votou a favor dos créditos de guerra". A própria recorrência de tempos em tempos de teorias milenaristas de Fim da História ${ }^{7}$ deveria servir de antídoto contra aqueles que querem ver o "Fim do Mundo" para as esquerdas com a queda do Muro de Berlim. Sem cair no exagero das visões "terminais" da crise atual, por outro lado é importante assumir sua seriedade e enfrentar os desafios teórico-práticos colocados por ela. É neste sentido que se insere o esforço deste artigo.

\section{CONCLUSÃO}

O fim da União Soviética e a queda do "Muro de Berlim" (i.e., do Leste europeu socialista) retiraram as bases materiais mais fortes que sustentavam o movimento comunista mundial. Talvez até exemplificando a tese de Marx de que são "as condições materiais da vida social que determinam a consciência dos homens", a esquerda comunista/socialista entrou em forte crise teórica da qual está tendo dificuldade de se recuperar.

Uma das alternativas teóricas encontradas (conscientemente ou por intermédio de "erro e acerto") foi a do tipo "terceira via" (Anthony Giddens) em que a confusão teórica da esquerda fica camuflada por uma confusão mais geral envolvendo esquerda e direita através da re- 
tirada dos rótulos ideológicos tradicionais que diferenciavam historicamente as políticas das duas áreas.

Mas essa confusão ideológica não é causada apenas por uma tentativa intencional de parte da esquerda de "trocar os sinais" para impedir identificações tradicionais. Partindo da hipótese lançada neste artigo (de que a esquerda tem papel preponderante na dinâmica dos sistemas partidários, sendo talvez o primum mobile das modificações radicais no sistema como um todo), era de se esperar que uma reorganização tão profunda na esquerda, como a queda da URSS e do Leste europeu socialista, levasse a "ondas de choque" pelo sistema como um todo, também afetando fortemente o centro e a direita. Todos esses poderosos fatores dinâmicos juntos, em um contexto de globalização e de incapacidade do regime capitalista de resolver diversas questões sociais básicas no âmbito planetário, levaram a uma forte reconfiguração do sistema político mundial que se encontra atualmente em situação de grande instabilidade.

(Recebido para publicação em dezembro de 2003) (Versão definitiva em novembro de 2004)

\section{NOTAS}

1. Expressão utilizada pela historiadora Izabel Cristina Gomes da Costa (2000).

2. Para uma descrição detalhada das diversas etapas da Perestroika, inclusive das lutas políticas da "fase de transição" de 1988, ver Segrillo (2001). Para uma visão geral das transformações na URSS / Rússia de 1985 em diante, ver Segrillo (2000; 2000a).

3. Além da política da vida, Giddens propõe outro pilar de orientação para os governos de terceira via, a generative politics pela qual o Estado procura "empoderar" (empower) os cidadãos, e não meramente os prover paternalisticamente com serviços públicos. "A política generativa é a política que procura incentivar que os indíviduos e grupos façam as coisas acontecerem, mais do que simplesmente deixar as coisas acontecerem a eles [...] Programas políticos radicais hoje em dia, eu argumento, devem ser baseados numa conjunção da política da vida e da política generativa." (Giddens, 1994:14-15; 246).

4. Ou esquerda, direita e centro, segundo alguns autores (como veremos mais adiante). 
5. É importante notar que nos estamos referindo a um nível teórico de alta abstração no qual a sociedade capitalista já está consolidada e a burguesia é a classe dominante. Nos casos históricos concretos nem sempre a realidade é tão nítida e límpida, sendo o grau de desenvolvimento do capitalismo em diversos países bastante heterogêneo, as divisões de classe nem sempre bem precisas e, conseqüentemente, as atuações partidárias (ou de facções) difíceis de classificar por motivos diversos do tema principal deste artigo.

6. Ou, se quisermos ficar nas explicações da história oficial, o perigo comunista (o "tenebroso" Plano Cohen/Intentona Comunista + infiltração comunista na república "sindicalista" de Jango) foi a explicação oficial para os golpes de Estado naquela época.

7. Por exemplo, pelo lado da esquerda, os inúmeros anúncios da crise "terminal" do capitalismo desde o século XIX. Pela "direita", tivemos Daniel Bell decretando o "Fim da Ideologia" já em 1960, com a vitória definitiva do capitalismo de welfare state sobre tanto o socialismo estatista quanto o liberalismo laissez-faire ingênuo, o que fica difícil de coadunar com o anúncio da derrota definitiva do welfare state e do socialismo estatista pela visão de um "Fim da História" neoliberal trombeteado nos anos 1990!

\section{REFERÊNCIAS BIBLIOGRÁFICAS}

BELL, Daniel. (1960), The End of Ideology: On the Exhaustion of Political Ideas in the Fifties. Glencoe, Free Press.

BOBBIO, Norberto. (1994), Destra e Sinistra: Ragioni i Significati di una Distinzione Politica. Roma, Donzelli.

CERRONI, Umberto. (1973), "Para una Teoria del Partido Politico", in U. Cerroni et alii, Teoría Marxista del Partido Político. Córdoba, Ediciones Pasado y Presente.

COSTA, Izabel Cristina Gomes da. (2000), Troca de Sinais: Uma Análise Histórica da Leitura do Jornal O Globo sobre as Reformas na União Soviética, 1985-1991. Dissertação de Mestrado, UFF, Niterói, RJ.

DUVERGER, Maurice. (1980), Os Partidos Políticos. Brasília, Editora da UnB.

FERNANDES, Luis. (1995), "Muito Barulho por Nada? O Realinhamento Político-Ideológico nas Eleições de 1994". Dados, vol. 38, noำ 1, pp. 107-144.

FUKUYAMA, Francis. (1992), O Fim da História e o Último Homem. Rio de Janeiro, Editora Rocco.

GIDDENS, Anthony. (1994), Beyond Left and Right. Cambridge, Polity Press. . (1998), The Third Way: The Renewal of Social Democracy. Cambridge, Polity Press. . (2000), The Third Way and its Critics. Cambridge, Polity Press. 
_. (2002), The Third Way Can Beat the Far Right. The Guardian [online]. [Consultado em 5/5/2003]. Disponível na internet <http://politics.guardian.co.uk/farright/comment/0,11375,709120,00.html $>$.

HIPPOLITO, Lúcia. (1985), De Raposas e Reformistas: O PSD e a Experiência Democrática Brasileira, 1945-64. Rio de Janeiro, Paz e Terra.

KINZO, Maria D’Alva Gil. (1993), Radiografia do Quadro Partidário Brasileiro. São Paulo, Konrad Adenauer Stiftung.

KIRCHHEIMER, Otto. (1966), "The Transformation of Western European Party Systems", in J. LaPalombara e M. Weiner (eds.), Political Parties and Political Development. Princeton, Princeton University Press.

LIMONGI, Fernando e FIGUEIREDO, Argelina Cheibub. (1995), “Partidos Políticos na Câmara dos Deputados: 1989-1994". Dados, vol. 38, no 3.

MENEGUELLO, Raquel. (1994), "Partidos e Tendências de Comportamento: O Cenário Político em 1994", in E. Dagnino (org.), Anos 90: Política e Sociedade no Brasil. São Paulo, Brasiliense.

. (1998), Partidos e Governos no Brasil Contemporâneo, 1985-1997. São Paulo, Paz e Terra.

MORANDI, Carlo. (1963), I Partiti Politici nella Storia d'Italia. Florença, Le Monnier.

NOVAES, Carlos Alberto. (1994), "Dinâmica Institucional de Representação". Novos Estudos Cebrap, ํㅡㅇㅡ.

SARTORI, Giovanni. (1966), “European Political Parties: The Case of Polarized Pluralism", in J. LaPalombara e M. Weiner (eds.), Political Parties and Political Development. Princeton, Princeton University Press.

. (1982), Partidos e Sistemas Partidários. Brasília, Editora da UnB.

SCULLY, Timothy R. (1990), Reappraising the Role of the Center: The Case of the Chilean Party System. Kellog Working Paper Series, no 143 [online]. [Consultado em 5/5/2003]. Disponível na internet <http://www.nd.edu/ kellogs/wps/143.PDF>.

SEGRILLO, Angelo. (2000), O Declínio da URSS: Um Estudo das Causas. Rio de Janeiro, Record.

__. (2000a), O Fim da URSS e a Nova Rússia. Petrópolis, RJ, Editora Vozes. . (2001), “As Diferentes Fases da Perestroika do Ponto de Vista Histórico e da Economia Política". Fronteiras: Revista de História, vol. 5, no 10. 


\section{GLOSSÁRIO}

PCB - Partido Comunista Brasileiro

PCUS - Partido Comunista da União Soviética

PFL - Partido da Frente Liberal

PL - Partido Liberal

PMDB - Partido do Movimento Democrático Brasileiro

PPB - Partido Progressista Brasileiro

PPS - Partido Popular Socialista

PSD - Partido Social Democrático

PSDB - Partido da Social Democracia Brasileira

PT - Partido dos Trabalhadores

PTB - Partido Trabalhista Brasileiro 


\section{ABSTRACT}

The Left-Right Confusion in the Post-Berlin Wall World: An Analysis and a Hypothesis

This article analyzes the modifications undergone by the concepts of "left" and "right" in the world after the fall of the Berlin Wall and the disintegration of the USSR. It sheds light on the consequences of these historical and theoretical changes in Brazil and postulates a hypothesis on the role of the left as the prime mover of radical alterations in the dynamic functioning of party systems as a whole.

Key words: political parties; left/center/right; political theory

\section{RÉSUMÉ}

La Confusion entre Gauche et Droite dans le Monde de l'Après Mur de Berlin: Une Analyse et une Hypothèse

Dans cet article, on analyse les transformations qu'ont subies les concepts de gauche et droite dans le monde après la chute du Mur de Berlin et la désagrégration de l'URSS. On y examine les conséquences au Brésil de ces changements historiques et théoriques en posant l'hypothèse selon laquelle la gauche est historiquement le primum mobile des changements radicaux dans la dynamique des systèmes de partis dans leur ensemble.

Mots-clé: partis politiques; gauche/centre/droite; théorie politique 